\title{
Serial position effects in semantic memory: Reconstructing the order of verses of hymns
}

\author{
ELIZABETH A. MAYLOR \\ University of Warwick, Coventry, England
}

\begin{abstract}
Serial position effects (primacy and recency) have been consistently demonstrated in both short-and long-term episodic memory tasks. The search for corresponding effects in semantic memory tasks (e.g., reconstructing the order of U.S. presidents) has been confounded by factors such as differential exposure to stimuli. In the present study, the stimuli were six-verse hymns that would have been sung from the first to the last verse by churchgoers on numerous occasions. Participants were presented with the verses of each hymn in random order and were required to reconstruct the correct order. Primacy and recency effects were significantly more evident for churchgoers than for nonchurchgoers. Moreover, error gradients were steeper than chance for churchgoers but not for nonchurchgoers; in other words, churchgoers' errors were more likely to be close to the correct position than further away. These findings provide the first unequivocal demonstration of serial position effects in semantic memory.
\end{abstract}

A common observation in episodic memory tasks, such as the immediate free recall of a list of words, is that the first and last few items are more likely to be recalled than the middle items (see Crowder, 1976, for examples). Similarly, in tasks requiring memory for serial order, such as order reconstruction, performance is superior at the beginning and end of lists (see Brown, Preece, \& Hulme, 2000, for examples). These serial position effects are termed primacy and recency, respectively. In many current textbooks, they are still explained within a dualstore account (e.g., Atkinson \& Shiffrin, 1968) such that primacy is attributed to the transfer of items (through rehearsal) to a long-term store, whereas recency reflects the immediate output of a limited-capacity short-term store (see, e.g., Bernstein, Clarke-Stewart, Penner, Roy, \& Wickens, 2000, p. 227; Carlson, Buskist, \& Martin, 2000, p. 249; Gross, 1996, p. 284).

However, at least one reason for doubting the standard textbook view as a complete explanation for serial position effects is that similar observations have been made in studies of long-term episodic memory. For example, primacy and recency effects have been demonstrated in studies of the recall of parking positions over 12 days (Pinto \& Baddeley, 1991), rugby matches played over a season (Baddeley \& Hitch, 1977), films seen during an academic year (Hitch \& Ferguson, 1991), and operas attended over 25 seasons (Sehulster, 1989). They have also been observed in studies of long-term memory using se-

The author is grateful to Janice Foster for help with stimulus selection, to Rachael Boulstridge and Jo Munday for collecting the data, to Gordon Brown and Greg Jones for helpful discussion, and to Robert Greene, Michael Masson, and David Rubin for useful comments on an earlier version of the article. Correspondence should be addressed to E. A. Maylor, Department of Psychology, University of Warwick, Coventry CV4 7AL, England (email: elizabeth.maylor@warwick.ac.uk). rial order reconstruction tasks (e.g., Nairne, 1991). Clearly, recency effects in such cases cannot be attributed to the output of a short-term store with a duration of seconds (cf. Bjork \& Whitten, 1974; Greene, 1986).

A related challenge to the traditional dual-store account was offered by Roediger and Crowder (1976), who drew on Tulving's (1972) distinction between episodic and semantic memory in attempting to extend serial position effects to a different memory system. Participants were asked to recall the names of as many presidents of the United States as possible in $5 \mathrm{~min}$. Regardless of whether correct ordering was required, classic primacy and recency effects were found, together with an additional peak in performance for Lincoln in the middle of the list. Roediger and Crowder argued that their results represented a true serial position effect in semantic memory and were therefore "quite difficult to reconcile with two-factor theories of the serial position effect" (p. 277). However, they also acknowledged that they had not definitely ruled out an alternative possibility_namely, that their results were "simply attributable to differences in degrees of learning the different presidents produced by differing frequencies of exposure" (p. 277).

Roediger and Crowder's (1976) study has since been replicated by Crowder (1993) and recently extended by Healy and her colleagues (Healy, Havas, \& Parker, 2000; Healy \& Parker, 2001). Healy used an order reconstruction task in which participants were presented with the complete list of United States presidents in random order and were required to sort them into correct chronological order. (Lists of vice presidents were also investigated in Healy \& Parker's, 2001, experiments.) Primacy and recency effects were again observed, together with a peak for Lincoln in the presidents' task. Importantly, very similar functions were also observed for participants' ratings of their familiarity with each name. Moreover, there were 
significant correlations between performance on the order reconstruction task and the familiarity ratings, indicating that prior frequency of exposure is probably responsible for these serial position effects in semantic memory (as Roediger and Crowder originally suspected). Similarly, with no control over learning, differential exposure could also explain the primacy effects observed by Rubin (1977) in his study of the recall of well-known passages of prose and poetry, including "The Preamble to the Constitution" and "Hamlet's Soliloquy."

Further search for serial position effects in semantic memory would seem to require lists of items that people encounter under incidental learning conditions in a fixed serial order on multiple occasions such that exposure to each item in the sequence is equivalent. The stimuli in the present study, hymns composed of six verses, came close to satisfying these constraints. It is assumed that hymns sung many times over several years become part of semantic memory. With the exception of the first verse (some of which is usually read out when a hymn number is announced in church), each verse of a hymn receives the same exposure.

The present task was to reconstruct the correct order of six-verse hymns when presented with the verses in a random order (cf. Healy et al., 2000; Healy \& Parker, 2001). Members of the Methodist denomination were chosen as the experimental group of participants for two main reasons. First, they have used the same hymnbook for many years (see below). Second, they invariably sing all the verses of hymns-note that hymnbooks in other denominations often indicate by asterisks verses that can be omitted. As a control for the possibility that verse order could be reconstructed from the content of the verses without one's ever having sung the hymn, the performance of the Methodists was compared with that of a group of nonchurchgoers. Data analysis included both correct performance as a function of serial position and error distributions as a function of distance from the correct position (see, e.g., Brown, Preece, \& Hulme, 2000).

\section{METHOD}

\section{Participants}

There were 54 participants (27 churchgoers; 27 nonchurchgoers). The churchgoers ( 9 men; 18 women) were members of the Methodist denomination who regularly attended church services and were from 19 to 83 years of age $(M=59.7 ; S D=14.3)$. The nonchurchgoers $(15$ men; 12 women) were from 20 to 85 years old $(M=55.5 ; S D=15.4)$. It was not possible to recruit nonchurchgoers who were completely unfamiliar with hymns, because most adults with the same ages and background as those of the Methodist group would have sung hymns at school and on occasional visits to church (weddings, funerals, etc.). However, their level of exposure was considerably lower than that of the churchgoers. All participants were native English speakers.

\section{Stimuli}

Eighteen six-verse hymns were selected from the current Methodist hymnbook (Hymns and Psalms, 1983). Care was taken to avoid hymns that contained clues to the order of the verses, such as those that related a story. Christmas carols were also not included in the set of stimuli on the basis that these would be familiar to nonchurch- goers. All the chosen hymns were exactly as they had appeared in the previous edition of the Methodist hymnbook (published in 1933), except for very minor alterations to wording. The verses of each hymn were printed on six separate cards.

\section{Design and Procedure}

The participants were presented with the six verses of a hymn in a random order. Their task was to place the verses in the correct serial order. This procedure was repeated for each of the 18 hymns. No time limit was imposed on performing the task, and the participants were encouraged to do their best even if they were unfamiliar with the hymns. The 18 hymns were presented in a different random order to each participant.

\section{RESULTS}

Figure 1 displays the overall placements of each of the six verses, separately for churchgoers and nonchurchgoers. For example, verse 1 was correctly placed in position 1 on $89 \%$ of occasions and incorrectly placed in positions $2-6$ on $2 \%, 3 \%, 2 \%, 1 \%$, and $2 \%$ of occasions by churchgoers. In comparison, verse 1 was correctly placed in position 1 on $42 \%$ of occasions and incorrectly placed in positions $2-6$ on $10 \%, 16 \%, 11 \%, 11 \%$, and $10 \%$ of occasions by nonchurchgoers. For churchgoers, each of the six functions peaked at its correct serial position, with errors generally dropping away systematically with increasing distance from the correct position. For nonchurchgoers, the functions did not always peak at the correct serial position and errors were more randomly distributed across the remaining positions.

If we consider correct responses only (i.e., verse 1 in position 1 , verse 2 in position 2 , and so on), churchgoers were clearly more successful overall than nonchurchgoers. Both groups showed evidence of superior performance in the first and last serial positions in comparison with the middle serial positions (primacy and recency effects, respectively), although these effects appeared more dramatic and extended for churchgoers than for nonchurchgoers. These observations were confirmed by an analysis of variance (ANOVA) on the percentages correct with group (churchgoers vs. nonchurchgoers) and serial position (1-6) as between- and within-participant variables, respectively. There was a significant effect of group $\left[F(1,52)=69.29, M S_{\mathrm{e}}=440.42, p<.0001\right]$, a significant effect of serial position $\left[F(5,260)=121.05, M S_{\mathrm{e}}=\right.$ $112.67, p<.0001]$, and a significant interaction between them $\left[F(5,260)=27.40, M S_{\mathrm{e}}=112.67, p<.0001\right]$.

Separate ANOVAs on percentages correct at serial positions 1-3 (primacy) and 4-6 (recency) also revealed significant main effects of group and serial position (all $p \mathrm{~s}<.0001)$. Crucially, the two-way interactions were significant (both $p \mathrm{~s}<.005$ ), indicating that primacy and recency effects were both significantly greater for churchgoers than for nonchurchgoers. This can be seen more clearly in Figure 2, which displays the differences (with $95 \%$ confidence intervals) in correct percentages between the two groups.

Finally, errors were analyzed further by recording the distance between the erroneous and correct positions for 
(a) Churchgoers

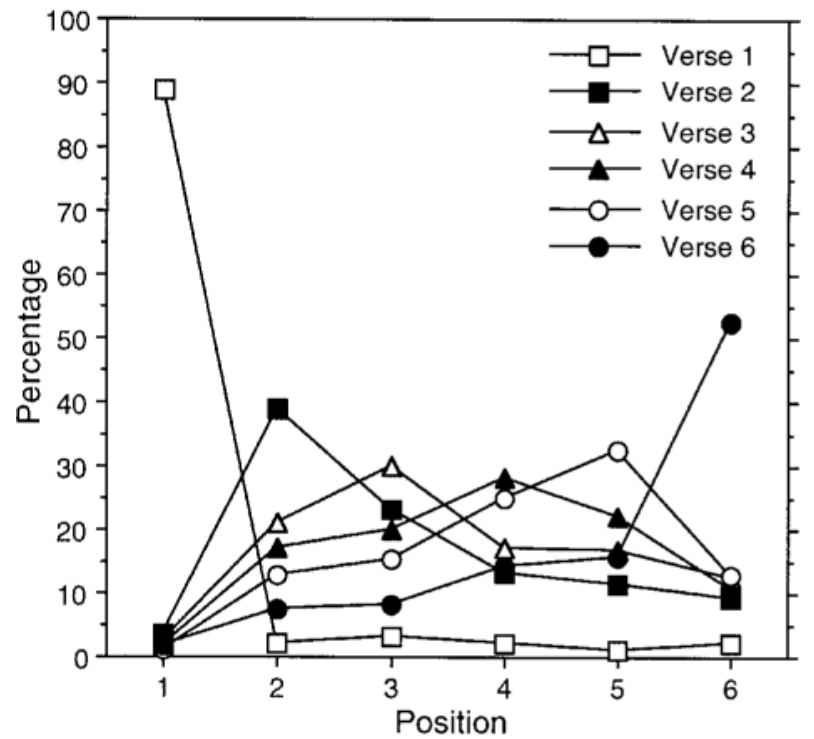

(b) Nonchurchgoers

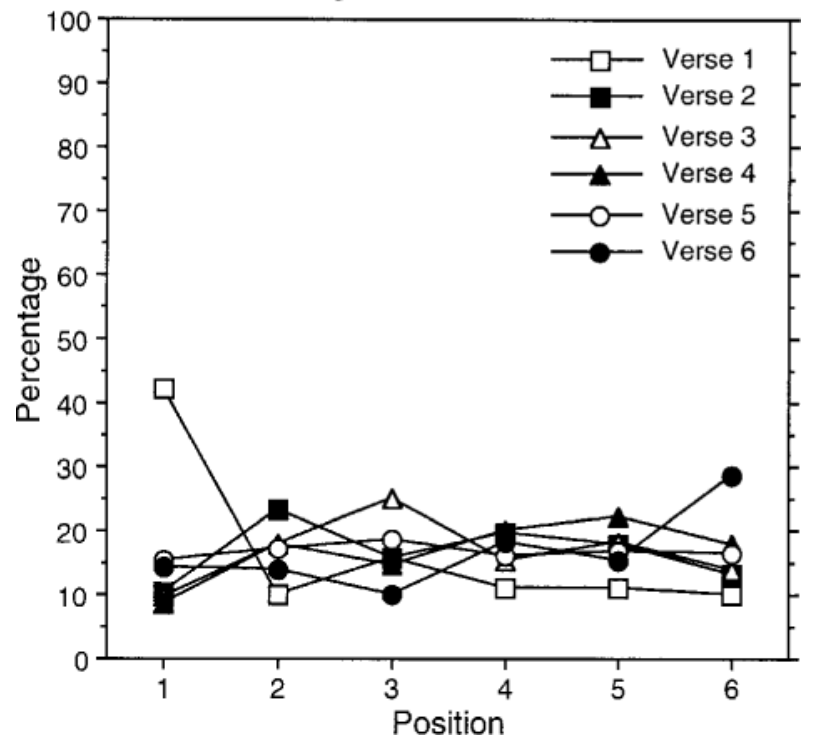

Figure 1. Mean percentages of verses 1-6 placed in serial positions 1-6 for (a) churchgoers and (b) nonchurchgoers.

each participant. For example, if a verse was placed in a position adjacent to the correct position, this was recorded as a separation of 1. Similarly, an erroneous placement of verse 2 in position 4 was recorded as a separation of 2 . Figure 3 shows the mean numbers of errors at each separation (1-5) expressed as percentages of the total numbers of errors (i.e., error gradients), for churchgoers and nonchurch goers. Also shown in dashed lines are the gradients that would be expected if errors were distributed randomly. The slopes of these chance gradients reflect the differing numbers of opportunities for errors at different separations. Both the observed and chance gra- dients were calculated for each participant and then averaged to produce the means and standard errors shown in Figure 3.

For churchgoers, the error gradient was clearly steeper than chance, with significantly more errors adjacent to the correct position, and significantly fewer errors at separations 2,3 and 4 , than expected by chance $[t(26)=$ $6.86,-2.15,-4.67$, and -3.55 , respectively, $p \mathrm{~s}<.05]$. In contrast, the overall error gradient for nonchurchgoers was similar to the chance gradient, although there were significantly more errors with a separation of 2 and fewer errors with a separation of 3 than expected by chance $[t(26)=4.06$ and -2.73 , respectively, $p s<.05]$. The observed data for churchgoers were then adjusted by subtracting the mean observed - chance differences for nonchurchgoers at each separation. The error gradient remained steeper than chance, with significantly more errors adjacent to the correct position $[t(26)=7.22]$ and significantly fewer errors at separations 2 and $4[t(26)=$ -5.48 and -2.07 , respectively] than expected by chance, with a marginal difference at a separation of $3[t(26)=$ $-1.89, p=.07]$.

\section{DISCUSSION}

To summarize the findings, clear primacy and recency effects were observed for churchgoers reconstructing the order of verses of hymns that had become part of semantic memory through repeated exposure over many years. Nonchurchgoers showed slightly better performance on the first and last verses in comparison with the remaining verses, which can probably be attributed to

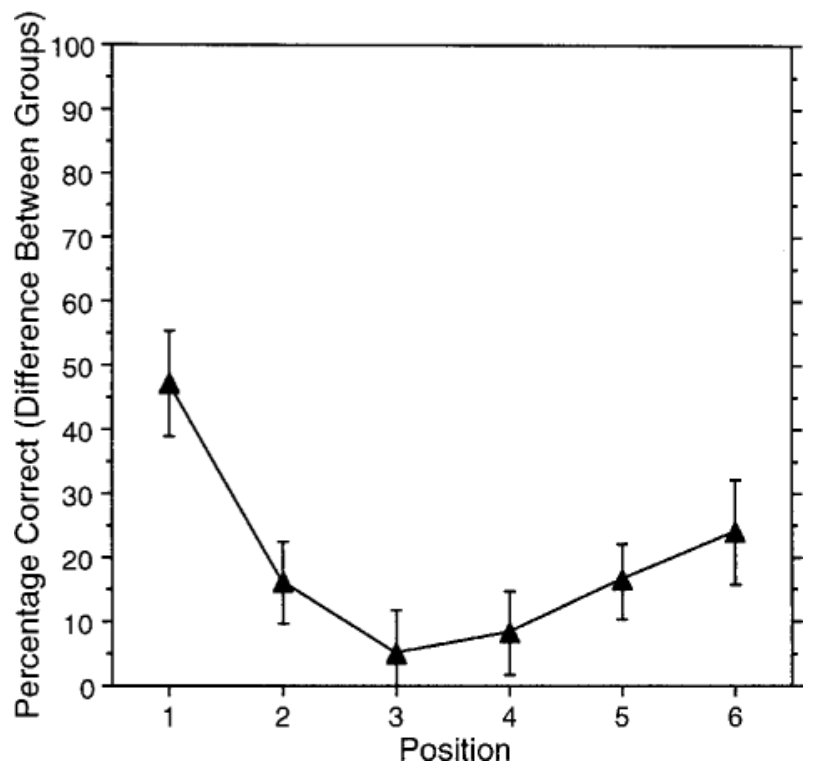

Figure 2. Mean differences between churchgoers and nonchurchgoers in percentages of verses correctly placed in serial positions 1-6. Error bars are $95 \%$ confidence intervals of the differences. 
(a) Churchgoers

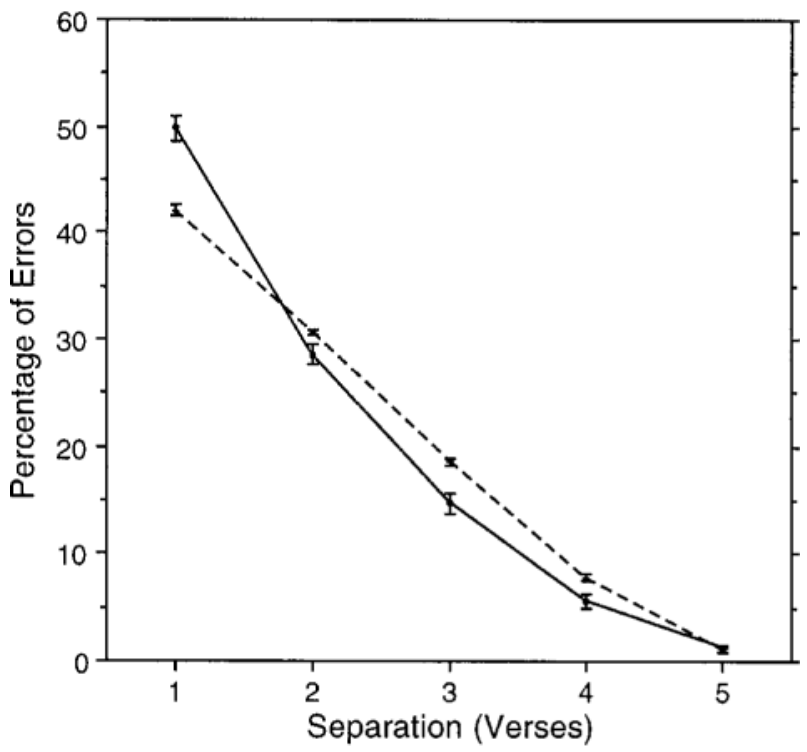

(b) Nonchurchgoers

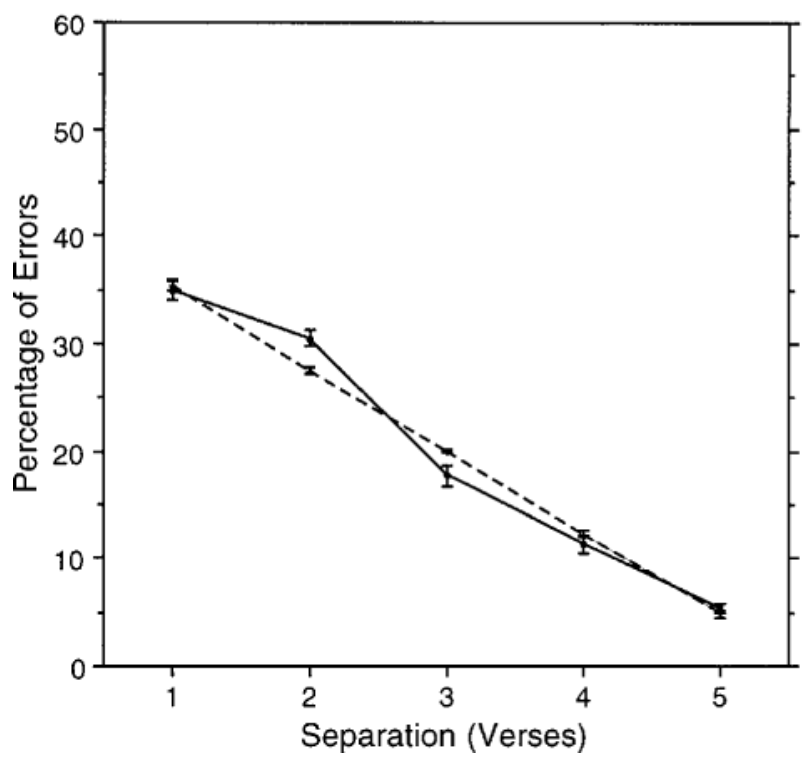

Figure 3. Mean numbers of errors produced at verse separations 1-5 as percentages of total errors (i.e., error gradients) for (a) churchgoers and (b) nonchurchgoers. Chance gradients are shown by the dashed lines; note that these differ for churchgoers and nonchurchgoers and are also nonlinear because they take into account the differing opportunities for errors at each separation. Error bars represent $\pm 1 S E$.

their occasional exposure to hymns (at school, weddings, etc.) and/or their ability to guess likely opening and closing verses from the content. Importantly, primacy and recency effects were both significantly larger for the churchgoers than for the nonchurchgoers (see Figure 2). Primacy was more striking than recency, but it has to be remembered that the first verse of a hymn probably receives greater exposure than the remaining verses through its inclusion in the announcement of a hymn. For church- goers, errors were significantly more likely to be adjacent to the correct position, and less likely to be further away, than would be expected if errors were distributed randomly. For nonchurchgoers, the pattern of errors was basically random, but with a small deviation from randomness in favor of responses two positions away, which is presumably a consequence of guessing on the basis of verse content. With this control pattern of errors taken into account, the errors of churchgoers remained systematically closer to the correct position than expected by chance.

The present results provide the first evidence of serial position effects in semantic memory that cannot be explained by differential exposure to the list items. Traditional interpretations of serial position effects in short-term episodic memory tasks obviously fail to provide a satisfactory account of the present findings for the same reason that they fail to account for serial position effects in longterm episodic memory tasks. Thus, recency in the latter cases (involving retention intervals of days or years) cannot be attributed to the immediate output of a short-term store. It is conceivable that similar serial position effects observed across different paradigms have different underlying explanations. But a more parsimonious alternative is that the present (and other) findings have a common origin in terms of relative temporal distinctiveness (Murdock, 1960, 2001) whereby items at the beginning and end of lists are remembered better because they differ most in temporal contextual terms from the remaining items (see also Crowder, 1976; Glenberg, Bradley, Kraus, \& Renzaglia, 1983; Glenberg \& Swanson, 1986; Neath, 1993a, 1993b). Similarly, models such as perturbation theory (Estes, 1972, 1997; Lee \& Estes, 1977, 1981), in which knowledge about the temporal-spatial context of items becomes less precise over time through a perturbation process, have been applied successfully to both short- and long-term recall (Nairne, 1991, 1992). An important feature of such models is that they predict that nearby items are more likely to be confused than widely separated items (see also Brown, Preece, \& Hulme, 2000). Exactly this pattern was observed in Figure 3 a where errors were not random but were more likely to be adjacent to the correct position than further away.

In conclusion, the present study provides the strongest evidence to date of serial position effects and systematic errors in semantic memory. Together with qualitatively similar findings in both short- and long-term episodic memory, the results offer a challenge to traditional dualstore accounts of serial position effects. In addition, they encourage the continued search for unifying principles to account for observations common to different time scales (see, e.g., Brown, Neath, \& Chater, 2000) and also, now, to both episodic and semantic memory.

\section{REFERENCES}

At KInson, R. C., \& ShIFfrin, R. M. (1968). Human memory: A proposed system and its control processes. In K. W. Spence \& J. T. Spence (Eds.), The psychology of learning and motivation: Advances in research and theory (Vol. 2, pp. 89-195). New York: Academic Press. 
Baddeley, A. D., \& Hitch, G. J. (1977). Recency re-examined. In S. Dornic (Ed.), Attention and performance VI (pp. 647-667). Hillsdale, NJ: Erlbaum.

Bernstein, D. A., Clarke-Stewart, A., Penner, L. A., Roy, E. J., \& Wickens, C. D. (2000). Psychology (5th ed.). Boston: Houghton Mifflin.

BJork, R. A., \& Whitten, W. B. (1974). Recency-sensitive retrieval processes in long-term free recall. Cognitive Psychology, 6, 173-189.

Brown, G. D. A., Neath, I., \& Chater, N. (2000). SIMPLE: A local distinctiveness model of scale-invariant memory and perceptual identification. Unpublished manuscript.

Brown, G. D. A., Preece, T., \& Hulme, C. (2000). Oscillator-based memory for serial order. Psychological Review, 107, 127-181.

Carlson, N. R., Buskist, W., \& Martin, G. N. (2000). Psychology: The science of behaviour. Harlow, U.K.: Pearson Education Ltd.

Crowder, R. G. (1976). Principles of learning and memory. Hillsdale, NJ: Erlbaum.

Crowder, R. G. (1993). Short-term memory: Where do we stand? Memory \& Cognition, 21, 142-145.

Estes, W. K. (1972). An associative basis for coding and organization in memory. In A. W. Melton \& E. Martin (Eds.), Coding processes in human memory (pp. 161-190). Washington, DC: Winston.

Estes, W. K. (1997). Processes of memory loss, recovery, and distortion. Psychological Review, 104, 148-169.

Glenberg, A. M., Bradley, M. M., Kraus, T. A., \& Renzaglia, G. J. (1983). Studies of the long-term recency effect: Support for a contextually guided retrieval hypothesis. Journal of Experimental Psychology: Learning, Memory, \& Cognition, 9, 231-255.

Glenberg, A. M., \& Swanson, N. G. (1986). A temporal distinctiveness theory of recency and modality effects. Journal of Experimental Psychology: Learning, Memory, \& Cognition, 12, 3-15.

Greene, R. L. (1986). Sources of recency effects in free recall. Psychological Bulletin, 99, 221-228.

Gross, R. (1996). Psychology: The science of mind and behaviour (3rd ed.). London: Hodder \& Stoughton.

Healy, A. F., Havas, D. A., \& Parker, J. T. (2000). Comparing serial position effects in semantic and episodic memory using reconstruction of order tasks. Journal of Memory \& Language, 42, 147-167.

Healy, A. F., \& Parker, J. T. (2001). Serial position effects in semantic memory: Reconstructing the order of the U.S. presidents and vice presidents. In H. L. Roediger III, J. S. Nairne, I. Neath, \& A. M. Surprenant (Eds.), The nature of remembering: Essays in honor of Robert G. Crowder (pp. 171-188). Washington, DC: American Psychological Association.
Hitch, G. J., \& Ferguson, J. (1991). Prospective memory for future intentions: Some comparisons with memory for past events. European Journal of Cognitive Psychology, 3, 285-295.

HyMnS AND PSALMS. (1983). London: Methodist Publishing.

LEE, C. L., \& ESTES, W. K. (1977). Order and position in primary memory for letter strings. Journal of Verbal Learning \& Verbal Behavior, 16, 395-418.

LEE, C. L., \& ESTES, W. K. (1981). Item and order information in shortterm memory: Evidence for multilevel perturbation processes. Journal of Experimental Psychology: Human Learning \& Memory, 7, 149-169.

Murdock, B. B. (1960). The distinctiveness of stimuli. Psychological Review, 67, 16-31.

Murdock, B. [B.] (2001). Analysis of the serial position curve. In H. L. Roediger III, J. S. Nairne, I. Neath, \& A. M. Surprenant (Eds.), The nature of remembering: Essays in honor of Robert G. Crowder (pp. 151-169). Washington, DC: American Psychological Association.

NAIRne, J. S. (1991). Positional uncertainty in long-term memory. Memory \& Cognition, 19, 332-340.

NAIRNE, J. S. (1992). The loss of positional certainty in long-term memory. Psychological Science, 3, 199-202.

Neath, I. (1993a). Contextual and distinctive processes and the serial position functions. Journal of Memory \& Language, 32, 820-840.

NeATH, I. (1993b). Distinctiveness and serial position effects in recognition. Memory \& Cognition, 21, 689-698.

Pinto, A. DA C., \& Baddeley, A. D. (1991). Where did you last park your car? Analysis of a naturalistic long-term recency effect. European Journal of Cognitive Psychology, 3, 297-313.

Roediger, H. L., III, \& Crowder, R. G. (1976). A serial position effect in recall of United States presidents. Bulletin of the Psychonomic Society, 8, 275-278.

Rubin, D. C. (1977). Very long-term memory for prose and verse. Journal of Verbal Learning \& Verbal Behavior, 16, 611-621.

SeHUlster, J. R. (1989). Content and temporal structure of autobiographical knowledge: Remembering twenty-five seasons at the Metropolitan Opera. Memory \& Cognition, 17, 590-606.

Tulving, E. (1972). Episodic and semantic memory. In E. Tulving \& W. Donaldson (Eds.), Organization of memory (pp. 590-600). New York: Academic Press.

(Manuscript received September 4, 2001; revision accepted for publication January 26, 2002.) 